\title{
Human Neutrophil-mediated Fungistasis against Histoplasma capsulatum Localization of Fungistatic Activity to the Azurophil Granules
}

\author{
Simon L. Newman, Lisa Gootee, and Joelle E. Gabay \\ Department of Medicine, Division of Infectious Diseases, University of Cincinnati College of Medicine, Cincinnati, Ohio 45267; \\ and the Beatrice and Samuel A. Seaver Laboratory, Division of Hematology-Oncology, \\ Department of Medicine, Cornell University Medical College, New York 10021
}

\section{Abstract}

Human neutrophils (PMN) demonstrated potent fungistatic activity against Histoplasma capsulatum (Hc) yeasts in a sensitive microassay that quantifies the growth of yeasts by the incorporation of $\left[{ }^{3} \mathbf{H}\right]$ leucine. At a PMN:yeast ratio of 1:2, PMN inhibited the growth of yeasts by 37\%. Maximum inhibition of $85 \%$ to $95 \%$ was achieved at a PMN/yeast ratio of 10:1 to 50:1. Opsonization of the yeasts in fresh or heat-inactivated serum was required for PMN-mediated fungistasis, but ingestion of the yeasts was not required. Recognition and phagocytosis of opsonized yeasts was via PMN complement receptor (CR) type $1\left(\mathrm{CR}_{1}\right), \mathrm{CR}_{3}$, and FcRIII (CD16). PMN fungistatic activity was evident by $2 \mathrm{~h}$, was maximum at $24 \mathrm{~h}$, and persisted up to $5 \mathrm{~d}$. In contrast, yeasts multiplied within monocytes to a greater extent than in culture medium alone. PMN from three patients with chronic granulomatous disease (CGD) inhibited the growth of Hc yeasts by an average of $97 \%$, compared with $86 \%$ in three normal controls. Furthermore, preincubation of $\mathrm{PMN}$ with the lysosomotropic agent $\mathrm{NH}_{4} \mathrm{Cl}$ inhibited fungistatic activity in a concentration-dependent manner. Finally, experiments with subcellular fractions of PMN demonstrated that the principal component of the fungistatic activity of PMN was localized in the azurophil granules. These data demonstrate that human $P M N$ possess potent fungistatic activity against Hc yeasts and further show that fungistasis is mediated by antimicrobial agents contained in the azurophil granules. (J. Clin. Invest. 1993. 92:624-631.) Key words: Histoplasma capsulatum - neutrophils - fungistasis • chronic granulomatous disease $\bullet$ azurophil granules

\section{Introduction}

The role of PMN in host defense against $H$. capsulatum $(\mathrm{Hc})^{1}$ is obscure (1). In animal model studies, PMN are the predomi-

Address reprint requests to Dr. Simon Newman, Division of Infectious Diseases, University of Cincinnati College of Medicine, 231 Bethesda Ave. (ML 560), Cincinnati, OH 45267.

Received for publication 28 August 1992 and in revised form 5 March 1993.

1. Abbreviations used in this paper: $\mathrm{CD}$, cytochalasin $\mathrm{D}$; $\mathrm{CGD}$, chronic granulomatous disease; $C R$, complement receptor; $\mathrm{CR}_{1}, \mathrm{CR}$ type 1 ; $\mathrm{CR}_{3}, \mathrm{CR}$ type 3; DPI, diphenylene iodonium bisulfate; G-CSF, granulocyte colony stimulating factor; HBSA, HBSS containing $0.25 \% \mathrm{BSA}$; Hc, Histoplasma capsulatum; NMMA, $N^{\mathrm{G}}$-monomethyl-L-arginine; PHS, pooled human serum.

J. Clin. Invest.

(c) The American Society for Clinical Investigation, Inc.

0021-9738/93/08/0624/08 \$2.00

Volume 92, August 1993, 624-631 nant inflammatory cell type in the lungs of outbred mice during the first $36 \mathrm{~h}$ after intranasal inoculation with Hc macroconidia. However, PMN do not appear to phagocytose these macroconidia, and the few yeasts that were present at $36 \mathrm{~h}$ were found only within macrophages (2). Baughman et al. (3) observed an intense PMN response in the lung at one week of infection after intranasal inoculation of C57BL/6 mice with yeasts of Hc strain G217B. By the second week, PMN had been largely supplanted by mononuclear cells characteristic of a granulomatous inflammatory response.

Previous studies in vitro have generated conflicting results with regard to PMN fungicidal activity against Hc yeasts. Howard (4) reported that in the presence of serum, glycogen-induced, peritoneal neutrophils of guinea pigs killed Hc yeasts after $3 \mathrm{~h}$ of incubation. In these experiments, killing was defined by altered stainability of the ingested Hc yeasts. However, definition of fungal death by alteration in staining properties has not been accepted widely (5), and these ultrastructural and tinctorial changes were not observed after phagocytosis by human PMN (6). Schaffner et al. (6) found that at a high phagocyte-to-fungus ratio, human PMN killed the mycelial phase, but not the yeast phase of $\mathrm{Hc}$, despite the fact that opsonized yeasts induced the PMN respiratory burst.

Most recently, it has been reported that human (7) and murine (8) neutrophils exhibited some fungistatic activity against Hc yeasts. In these experiments, PMN and yeasts were incubated in the presence of fresh serum for varying periods of time, the PMN lysed, and the remaining viable yeasts quantified by culture on brain heart infusion agar containing $10 \%$ sheep blood. Using this methodology, PMN were found to inhibit the growth of yeasts by $47 \%$, compared with yeasts cultured in media alone. However, fungistasis was demonstrated only if the PMN/yeast ratio was 500:1.

In previous studies, we demonstrated that phagocytosis of serum-opsonized $\mathrm{Hc}$ yeasts by human neutrophils stimulated a strong respiratory burst and that superoxide anion $\left(\mathrm{O}_{2}^{-}\right)$became trapped within the phagocytic vacuole (9). Thus, yeasts should be directly exposed to toxic oxygen metabolites. The present investigation was designed to $(a)$ establish a sensitive microassay to quantify PMN fungistatic activity against Hc yeasts, $(b)$ evaluate the ability of various cytokines to induce PMN fungicidal activity against Hc yeasts, and $(c)$ determine the mechanism(s) of PMN-mediated fungistasis. Our results demonstrate that human $P M N$ possess potent fungistatic activity against $\mathrm{Hc}$ yeasts that can be detected at very low ratios of PMN to yeasts and that can persist up to five days. We present evidence that the principal component of the fungistatic activity of neutrophils is localized in the azurophil granule fraction.

\section{Methods}

Reagents. PMA, cytochalasin D (CD), SOD, catalase, and mannitol, were purchased from Sigma Chemical Co. (St. Louis, MO). PMA and 
CD were dissolved in DMSO at a concentration of $1 \mathrm{mg} / \mathrm{ml}$ and small aliquots were stored at $-70^{\circ} \mathrm{C}$ until used. $N^{\mathrm{G}}$-monomethyl-L-arginine (NMMA) was purchased from Calbiochem (La Jolla, CA). Diphenylene iodonium bisulphate (DPI) was a gift of Dr. Andrew Cross, The Scripps Research Institute (La Jolla, CA). A 1-mM stock concentration of DPI was prepared in DMSO and stored at $-80^{\circ} \mathrm{C}$. DPI was diluted into medium to the desired concentrations just before use. Recombinant IL-3, GM-CSF, granulocyte CSF (G-CSF), IFN $\gamma$, and IL-8 were a gift from Immunex Corporation (Seattle, WA). Human serum from eight individual donors was pooled and stored in $200 \mu \mathrm{l}$ aliquots at $-80^{\circ} \mathrm{C}$. This pooled human serum (PHS) contained no complement fixing antibody against Hc.

Antibodies. mAbs TS-1 / 22 (10), specific for CD1 la (LFA-1); IB4 (11), specific for CD18 ( $\beta$ chain); and 3G8 (12), specific for the FcRIII of PMN, were a gift of Dr. Samuel Wright, The Rockefeller University, New York. MN-41 (13), specific for CD11b $\left(\mathrm{CR}_{3}\right)$, was provided by Dr. Allison Eddy, University of Minnesota Medical School, Minneapolis, MN. LeuM5 (14), specific for CD11c (p150,95) was a gift of Dr. Louis Lanier, Becton Dickinson Immunocytometry Systems (Mountain View, CA). A polyclonal rabbit $F\left(a b^{\prime}\right)_{2}$ anti-CR was prepared as described (15).

Yeasts. The yeast phase of Hc strain G217B was grown in HMM medium (16) at $37^{\circ} \mathrm{C}$ with orbital shaking at $150 \mathrm{rpm}$. After $2 \mathrm{~d}$, yeasts were harvested by centrifugation, washed three times in HBSS containing $20 \mathrm{mM}$ Hepes and $0.25 \%$ BSA (HBSA), and resuspended to $30 \mathrm{ml}$ in HBSA. Large aggregates were removed by centrifugation at $200 \mathrm{~g}$ for $5 \mathrm{~min}$ at $4^{\circ} \mathrm{C}$. The top $2-5 \mathrm{ml}$ were removed, and the single cell suspension obtained was standardized to $1 \times 10^{5} / \mathrm{ml}$ in RPMI 1640 containing $10 \mu \mathrm{g} / \mathrm{ml}$ of gentamicin (17).

Fluorescein labeling of $\mathrm{Hc}$ yeasts. For attachment assays, heatkilled yeasts were incubated at $2 \times 10^{8} / \mathrm{ml}$ in $0.1 \mathrm{mg} / \mathrm{ml} \mathrm{FITC} \mathrm{in} 0.5 \mathrm{M}$ carbonate-bicarbonate buffer, $\mathrm{pH} 9.5$ for $60 \mathrm{~min}$ at $37^{\circ} \mathrm{C}$, washed twice in HBSA, and resuspended to $2 \times 10^{8} / \mathrm{ml}$ in HBSS containing $10 \%$ PHS. After incubation for $20 \mathrm{~min}$ at $37^{\circ} \mathrm{C}$, the yeasts were washed twice in HBSA, and then were resuspended to $7 \times 10^{7} / \mathrm{ml}(9,18)$.

Isolation of human phagocytes. Human monocytes and neutrophils were isolated from peripheral blood by dextran sedimentation and Ficoll-Paque (Pharmacia LKB Biotechnology Inc., Piscataway, NJ) centrifugation $(9,18)$. The mononuclear cells were harvested from the top of the Ficoll-Paque gradient, washed in HBSS containing $20 \mathrm{mM}$ Hepes and $10 \mu \mathrm{g} / \mathrm{ml}$ gentamicin (Hanks' Hepes), and were suspended to $3-4 \times 10^{6} / \mathrm{ml}$ in Hanks' Hepes containing $0.1 \%$ autologous serum. 1/10th $\mathrm{ml}$ vol of mononuclear leukocytes was aliquoted into the wells of 96-well tissue culture plates (Corning Medical, Cambridge, MA), and the monocytes were allowed to adhere for $1 \mathrm{~h}$ at $37^{\circ} \mathrm{C}$ in $5 \% \mathrm{CO}_{2}-95 \%$ air. The adherent monocytes were washed vigorously with Hanks' Hepes to remove the lymphocytes and then incubated with $\mathrm{Hc}$ yeasts as described below.

PMN were harvested from the bottom of the Ficoll-Paque gradient by suspending the cells in $5 \mathrm{ml}$ of $0.2 \% \mathrm{NaCl}$ to lyse contaminating erythrocytes. Isotonicity was restored with $5 \mathrm{ml}$ of $1.6 \% \mathrm{NaCl}$. PMN were washed twice in RPMI 1640 containing $10 \mu \mathrm{g} / \mathrm{ml}$ of gentamicin and standardized to the appropriate concentration in the same medium.

Subcellular fractionation of PMN and extraction of granules. Subcellular fractions of PMN were prepared as described previously (19). Briefly, PMN from $1 \mathrm{U}$ of blood were suspended at $2 \times 10^{7} / \mathrm{ml}$ in PBS for $15 \mathrm{~min}$ at $4^{\circ} \mathrm{C}$. The cells were centrifuged at $130 \mathrm{~g}$ for $10 \mathrm{~min}$ at $4^{\circ} \mathrm{C}$, and the pellet was resuspended at $4^{\circ} \mathrm{C}$ in relaxation buffer containing $100 \mathrm{mM} \mathrm{KCl}, 3 \mathrm{mM} \mathrm{NaCl}, 1 \mathrm{mM} \mathrm{ATP}(\mathrm{Na})_{2}, 3.5 \mathrm{mM} \mathrm{MgCl}$, $10 \mathrm{mM}$ Pipes, pH 7.3. PMN were lysed by nitrogen cavitation, and nuclei and intact cells were removed by centrifugation at $500 \mathrm{~g}$ for 10 $\min$ at $4^{\circ} \mathrm{C}$. The postnuclear supernatant was centrifuged for $15 \mathrm{~min}$ at 20,000 rpm (SS 34 rotor; Sorvall Instruments, Newtown, CT) on a discontinuous Percoll density gradient. $1-\mathrm{ml}$ fractions were collected at $4^{\circ} \mathrm{C}$ and assayed for specific markers of azurophil granules, specific granules, and plasma membrane (19). Percoll was removed from pooled fractions by centrifugation at $180,000 \mathrm{~g}$ for $2 \mathrm{~h}$ (SW41 rotor; Beckman Instruments, Inc., Palo Alto, CA ). The layer that sedimented above the packed Percoll was resuspended in relaxation buffer. Azurophil granules, specific granules, and plasma membrane fractions were extracted by seven freeze-thaw cycles in dry ice/acetone with a 15-sec sonication pulse between each cycle (19). All subcellular fractions were stored at $5 \times 10^{7}$ cell equivalents $/ \mathrm{ml}$ at $-70^{\circ} \mathrm{C}$.

Chronic granulomatous disease (CGD) patients. Patient 1 is a 20 yr-old white male with CGD who presented in the first year of life with failure to gain weight, chronic diarrhea, and recurrent pneumonia. His clinical course has been complicated by recurrent pneumonia. He has been on continuous prophylaxis with trimethoprim/sulfamethoxazole, and has been on recombinant IFN $\gamma$ since March 1990. His current complications include chronic pneumonia caused by Aspergillus, treated with amphotericin B.

Patient 2 is a 17 -yr-old white female who was the product of a consanguineous relationship. She was diagnosed at 4 mo of age when she presented with osteomyelitis secondary to infection with Serratia marcescens. Her clinical course has been complicated by chronic colitis, esophageal stenosis, and intestinal cutaneous fistulae. She has been treated with trimethoprim/sulfamethoxazole and recombinant IFN $\gamma$ since November 1988. Her neutrophils, which fail to generate superoxide anion in response to PMA, contain normal levels of cytochrome $\mathrm{b}_{558}$, and are deficient in p47-phox in cell homogenates (J. T. Curnutte, personal communication ).

Patient 3 is a 13 -yr-old white male who was hospitalized at age 5 with Nocardia pneumonia. His clinical course has been complicated by gastroenteritis, pneumonia, and cervical adenopathy. He has been on rifampin prophylaxis since 1989 . He has never received IFN $\gamma$.

Attachment assay. PMN $\left(2.5 \times 10^{3}\right)$ were adhered in the wells of a Terasaki tissue culture plate (Miles Scientific Division, Naperville, IL) for $1 \mathrm{~h}$ at $37^{\circ} \mathrm{C}$ in $5 \% \mathrm{CO}_{2}-95 \%$ air and washed twice in PBS containing $0.68 \mathrm{mM} \mathrm{Ca}$ and $0.5 \mathrm{mM} \mathrm{Mg}\left(\mathrm{PBS}^{++}\right) .5 \mu \mathrm{l}$ of $\mathrm{mAb}(50 \mu \mathrm{g} / \mathrm{ml})$ or $\mathrm{PBS}^{++}$were added to each well and the cells incubated for $30 \mathrm{~min}$ at $4^{\circ} \mathrm{C} .5 \mu \mathrm{l}$ of serum opsonized FITC-labeled yeasts $\left(7 \times 10^{7} / \mathrm{ml}\right)$ then were added to the monolayers, and the mixture was incubated for 30 min at $37^{\circ} \mathrm{C}$. Unattached organisms were removed by washing with $\mathrm{PBS}^{++}$, and the monolayers fixed in $1 \%$ paraformaldehyde. Attachment of the organisms was quantified via fluorescence microscopy on an inverted microscope (Diaphot; Nikon Inc., Instr. Group, Melville, NY) by counting 100 cells/well. Results are expressed as the attachment index, the total number of organisms bound per 100 PMN $(9,18)$.

Quantitation of neutrophil fungistatic activity. PMN fungistatic activity against $\mathrm{Hc}$ yeasts was quantified by the incorporation of $\left[{ }^{3} \mathrm{H}\right]-$ leucine into growing yeasts (20). 50- $\mu \mathrm{l}$ aliquots of PMN, $50 \mu \mathrm{l}(5$ $\times 10^{3}$ ) of viable yeasts, and $10 \mu$ l of PHS were added to the wells of a 96-well tissue culture plate and incubated at $37^{\circ} \mathrm{C}$ in $5 \% \mathrm{CO}_{2}-95 \%$ air. After incubation for varying periods of time, the plates were centrifuged at $2000 \mathrm{rpm}$. The supernatant was carefully aspirated through a 27 gauge needle, and $50 \mu \mathrm{l}(1.5 \mu \mathrm{Ci})$ of $\left[{ }^{3} \mathrm{H}\right]$ leucine $(50 \mu \mathrm{Ci} / \mathrm{mmol}$, New England Nuclear, Boston, MA) in sterile water, and $5 \mu \mathrm{l}$ of a $10 \times$ yeast nitrogen broth (Difco Laboratories, Inc., Detroit, MI) was added to each well. After further incubation for $24 \mathrm{~h}$ at $37^{\circ} \mathrm{C}, 50 \mu \mathrm{l}$ of L-leucine and $50 \mu \mathrm{l}$ of sodium hypochlorite were added to each well. The contents of the wells were harvested onto glass fiber filters using an automated harvester (Skatron, Inc., Sterling, VA). The filters were placed into scintillation vials, scintillation cocktail added, and the vials were counted in a liquid scintillation spectrometer (LS 7000; Beckman Instruments, Inc.).

The growth of yeasts in adherent monocytes was quantified in an identical manner, except that $5 \times 10^{3}$ yeasts was added to the cell monolayer in $0.1 \mathrm{ml}$ of medium. Control wells contained yeasts only, and the counts in these wells ranged from $20,000-200,000 \mathrm{cpm}$. The data is expressed as the percent inhibition of the growth of yeasts, which is defined as $1-(\mathrm{cpm}$ from yeasts plus $\mathrm{PMN} / \mathrm{cpm}$ from yeasts in medium alone $) \times 100$. All experiments were performed in triplicate, 
and all experiments were performed at least three times with cells from different donors. The data are presented as the mean \pm SEM.

Quantitation of the fungistatic activity of PMN subcellular fractions. Specific granule, azurophil granule, plasma membrane, and cytosol fractions were diluted to $2 \times 10^{7}$ cell equivalents $/ \mathrm{ml}$ in citrate phosphate buffer, $\mathrm{pH} 5.0$, and stored in $0.1-\mathrm{ml}$ aliquots at $-70^{\circ} \mathrm{C}$. For each experiment, the fractions were further diluted in citrate phosphate buffer as required. Hc yeasts were suspended to $5 \times 10^{4} / \mathrm{ml}$ in $\mathrm{HMM}$ medium diluted $1 / 25$ in $10 \mathrm{mM}$ phosphate buffer, $\mathrm{pH} 6.0 .0 .1 \mathrm{ml}$ of yeasts and $0.025 \mathrm{ml}$ of PMN fractions containing varying amounts of cell equivalents were incubated in 96-well tissue culture plates at $37^{\circ} \mathrm{C}$ in $5 \% \mathrm{CO}_{2}-95 \%$ air. Control wells contained $0.1 \mathrm{ml}$ of yeasts and 0.025 $\mathrm{ml}$ of citrate phosphate buffer. After incubation for varying periods of time, the plates were pulsed with $\left[{ }^{3} \mathrm{H}\right]$ leucine and harvested as described above. All experiments were performed in triplicate, and the data are presented as the mean \pm SEM of the percent inhibition of growth of at least three separate experiments.

\section{Results}

Concentration-dependent PMN fungistatic activity against $H c$ yeasts. In our initial experiments, increasing numbers of PMN were incubated with $5 \times 10^{3}$ viable yeasts for $24 \mathrm{~h}$ at $37^{\circ} \mathrm{C}$. As our previous studies (9) had indicated that PMN ingested few Hc yeasts in the absence of fresh human serum, 10\% PHS was included in the assay. Fungistasis was quantified by comparing the incorporation of $\left[{ }^{3} \mathrm{H}\right]$ leucine into yeasts incubated in medium alone, and yeasts incubated with PMN as described in Methods. Fig. 1 shows that at a PMN/yeast ratio of 1:2, PMN inhibited the growth of yeasts by $37 \%$. Maximum inhibition of growth of $85-95 \%$ was achieved at a PMN/yeast ratio of 10:1 to $50: 1$.

Time course of PMN-mediated fungistasis. The kinetics of PMN fungistatic activity was quantified after incubating PMN and yeasts at a ratio of 50:1 for varying periods of time. PMNmediated fungistasis against $\mathrm{Hc}$ yeasts could be detected as early as $2 \mathrm{~h}$, and was maximum after $24 \mathrm{~h}$ of incubation (Fig. 2 ). The viability of PMN after $24 \mathrm{~h}$ was $95 \%$, as determined by trypan blue dye exclusion. PMN fungistatic activity was maintained at a high level, even after $3 \mathrm{~d}$ of culture, at which time the

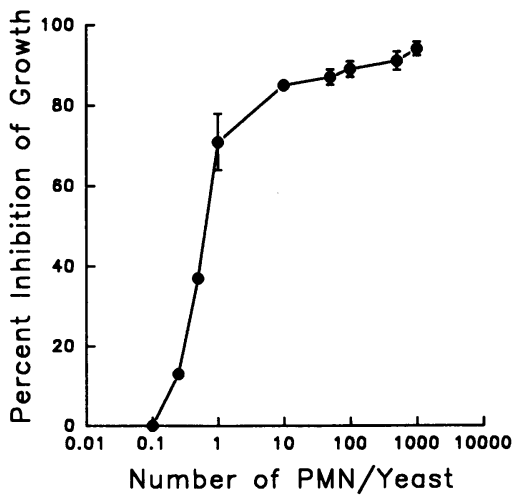

Figure 1. Concentration-dependent PMN fungistatic activity against $\mathrm{Hc}$ yeasts. Yeasts $\left(5 \times 10^{3}\right)$ and varying numbers of PMN were incubated for $24 \mathrm{~h}$ at $37^{\circ} \mathrm{C}$ in RPMI 1640 containing $10 \%$ PHS and $10 \mu \mathrm{g} / \mathrm{ml}$ of gentamicin. The supernatant then was removed and $50 \mu \mathrm{l}(1.5$ $\mu \mathrm{Ci})$ of $\left[{ }^{3} \mathrm{H}\right]$ leucine and $5 \mu \mathrm{l}$ of a $10 \times$ yeast ni-

trogen broth were added to all the wells. After further incubation for $24 \mathrm{~h}$ at $37^{\circ} \mathrm{C}, 50 \mu \mathrm{l}$ of L-leucine and $50 \mu \mathrm{l}$ of sodium hypochlorite were added to each well. The contents of the wells were then harvested onto glass fiber filters and prepared for liquid scintillation counting as described in Methods. The data are expressed as the percent inhibition of the growth of yeasts and are presented as the mean \pm SEM from four experiments.

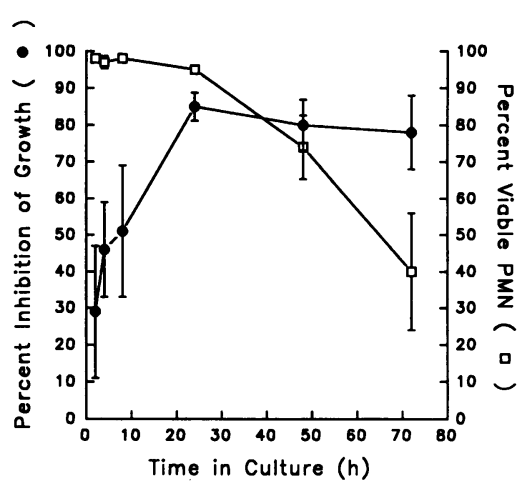

Figure 2. Time course of PMN-mediated fungistasis. PMN and yeasts at a ratio of 50:1 were incubated for varying periods of time at $37^{\circ} \mathrm{C}$ in medium containing $10 \%$ PHS. A separate set of wells containing only PMN was used to assess PMN viability by trypan blue dye exclusion. The data are the mean \pm SEM of three experiments. percentage of viable PMN had decreased to $40 \%$. The total number of PMN remained constant throughout the $3 \mathrm{~d}$ of culture. Cultures of PMN and yeasts were observed by phase contrast microscopy for up to $7 \mathrm{~d}$. From days 2 to 5 , the PMN were localized in discrete aggregates. By day 4, intracellular yeasts could be seen within the PMN. Remarkably, no extracellular yeasts were observed until the sixth day of culture.

Opsonization in serum is required for PMN fungistatic activity against $\mathrm{Hc}$ yeasts. To determine the requirement for serum opsonization in PMN-mediated fungistasis against Hc yeasts, PMN and yeasts were incubated in RPMI 1640 containing no serum or in RPMI containing various serum supplements. PMN exhibited no fungistatic activity in the absence of serum (Fig. 3). PMN inhibited the growth of yeasts by $80 \%$ in medium containing $10 \%$ heat-inactivated PHS. Optimum fungistasis (92\% inhibition of yeast growth) was achieved with the addition of $10 \%$ fresh PHS.

Previous studies in our laboratory had shown that Hc yeasts multiply within human monocytes with an intracellular generation time of about $13 \mathrm{~h}$ (17). Therefore, we quantified the growth of Hc yeasts in human monocytes in parallel with the studies on PMN. In contrast to the results obtained with neutrophils, Hc yeasts grew within monocytes more rapidly than they

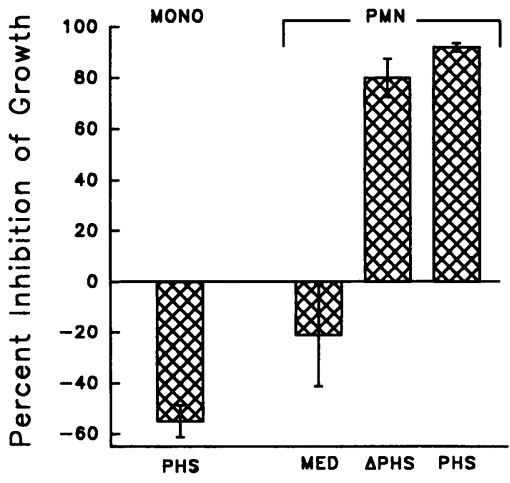

Figure 3. Opsonization in serum is required for PMN fungistatic activity against $\mathrm{Hc}$ yeasts. PMN and yeasts at a ratio of 50:1 were incubated for $24 \mathrm{~h}$ at $37^{\circ} \mathrm{C}$ in RPMI 1640 alone or in medium containing $10 \%$ PHS or $10 \%$ heatinactivated PHS (^PHS). Monocytes from the same donors were adhered in 96-well plates, washed to remove lymphocytes, and then were incubated with $5 \times 10^{3}$ yeasts for $24 \mathrm{~h}$ at $37^{\circ} \mathrm{C}$ in medium containing $10 \%$ PHS. The contents of the wells then were processed as described in Fig. 1. An average of $5 \times 10^{4}$ monocytes were adherent in each well. The data are the mean \pm SEM of 3-7 experiments. Bars extending downward into the negative numbers indicate that yeasts grew better under these conditions than in medium alone. 
grew in tissue culture medium alone (Fig. 3), confirming our previous observations (17). Thus, under identical conditions, $\mathrm{Hc}$ yeasts grow within monocytes, but are inhibited by PMN.

To determine if ingestion of yeasts was required for neutrophil-mediated fungistasis, PMN and yeasts were incubated for $24 \mathrm{~h}$ in the presence and absence of $1 \mu \mathrm{g} / \mathrm{ml} \mathrm{CD}$. In the absence of CD, PMN inhibited the growth of yeasts by $92 \pm 1.2 \%$ (mean \pm SEM, $n=3$ ); in the presence of CD, inhibition was $94 \pm 2.4 \%$.

Complement receptors and $F c$ receptors participate in the attachment of opsonized Hc yeasts to PMN. As opsonization in fresh serum was required for optimum PMN fungistatic activity, we sought to identify the specific receptors involved in recognition and phagocytosis. Monolayers of PMN were preincubated with antireceptor antibodies for $30 \mathrm{~min}$ at $4^{\circ} \mathrm{C}$ and then incubated with opsonized FITC-labeled yeasts for $30 \mathrm{~min}$ at $37^{\circ} \mathrm{C}$. As shown in Table I, mAb MN-41, specific for the iC $3 b$ binding site in $\mathrm{CR}_{3}(13)$, inhibited binding of yeasts to $P M N$ by $33 \%$. A polyclonal antibody to $\mathrm{CR}_{1}$ inhibited yeast binding by $34 \%$, and mAb 3G8, specific for FcRIII, inhibited attachment by $22 \%$. The inhibition obtained with a combination of anti$\mathrm{CR}_{1}$ and anti-CR $\mathrm{CR}_{3}$ antibodies was additive, inhibiting the attachment of yeasts to PMN by $63 \%$. When mAb 3G8 was added to this anti-CR "cocktail," the binding of yeasts to PMN was inhibited by $76 \%$. mAbs specific for the LPS binding site in $\mathrm{CR}_{3}$ (904) (21), or for CD1 la and CD1 1 c inhibited yeast binding to PMN by $<20 \%$. mAb IB4, specific for CD18, inhibited attachment of opsonized yeasts to PMN by $42 \%$.

Effect of cytokines, CSF, and PMA on PMN-mediated fungistasis. We next sought to determine if PMN fungicidal activity could be induced by biological response modifiers that are known to enhance PMN respiratory burst and cytotoxic activity. PMN and yeasts were mixed in a ratio of 10:1 and incubated in medium for $24 \mathrm{~h}$ in the presence or absence of cytokines, CSF, or PMA. At the highest concentrations tested ( 100 $\mathrm{ng} / \mathrm{ml}$ ), neither IL-8, IL-3, GM-CSF, G-CSF, IFN $\gamma$, nor PMA $(1 \mathrm{ng} / \mathrm{ml})$ induced PMN fungicidal activity or enhanced PMN-mediated fungistasis (data not shown).

Table I. $C R_{1}, C R_{3}$, and FcR Mediate Attachment of Opsonized H. capsulatum Yeasts to Human Neutrophils

\begin{tabular}{|c|c|c|c|}
\hline Antibody & Specificity & $\begin{array}{l}\text { Attachment } \\
\text { index }\end{array}$ & Inhibition \\
\hline & & & $\%$ \\
\hline None & - & $559 \pm 41^{\ddagger}$ & - \\
\hline TS $1 / 22$ & CD11a & $468 \pm 37$ & 16 \\
\hline MN-41 & CD11b & $374 \pm 40$ & 33 \\
\hline 904 & $\mathrm{CD} 1 \mathrm{~b}$ & $478 \pm 53$ & 14 \\
\hline LeuM5 & CD11c & $497 \pm 30$ & 11 \\
\hline $1 \mathrm{~B} 4$ & $\mathrm{CD} 18$ & $321 \pm 32$ & 42 \\
\hline $\mathrm{F}\left(\mathrm{ab}^{\prime}\right)_{2} \alpha \mathrm{CR}_{1}$ & $\mathrm{CD} 35$ & $371 \pm 36$ & 34 \\
\hline$\alpha \mathrm{CR}_{1}+\alpha \mathrm{CR}_{3}$ & $\mathrm{CD} 35+\mathrm{CD} 11 \mathrm{~b}$ & $206 \pm 50$ & 63 \\
\hline $3 G 8$ & CD16 (FcRIII) & $434 \pm 18$ & 22 \\
\hline$\alpha \mathrm{CR}_{1}+\alpha \mathrm{CR}_{3}+\alpha \mathrm{FcR}$ & $\mathrm{CD} 35, \mathrm{CD} 11 \mathrm{~b}, \mathrm{CD} 16$ & 133 & 76 \\
\hline
\end{tabular}

Monolayers of PMN were incubated with antibodies $(50 \mu \mathrm{g} / \mathrm{ml})$ for 30 $\min$ at $4^{\circ} \mathrm{C}$ and then incubated with opsonized FITC-labeled Hc yeasts for $30 \mathrm{~min}$ at $37^{\circ} \mathrm{C}$. ${ }^{*}$ Attachment index, the total number of yeasts bound per $100 \mathrm{PMN}$. ${ }^{\ddagger} \operatorname{Mean} \pm \operatorname{SEM}(n=2-4)$.
Inhibitors of nitric oxide (NO) production and oxygen radical scavengers do not inhibit PMN fungistatic activity against $H c$ yeasts. It has been reported that human PMN produce NO (22-24), an agent that appears to play an important role in the antimicrobial activity of mouse $\operatorname{M} \phi(25,26)$. To explore a possible role for NO in PMN fungistasis against $\mathrm{Hc}$ yeasts, $\mathrm{PMN}$, and yeasts were incubated for $24 \mathrm{~h}$ in the presence of 1 $\mathrm{mM} N^{\mathrm{G}}$-monomethyl-L-arginine (NMMA) $(27,28)$, or $10 \mu \mathrm{M}$ DPI (29). However, none of these reagents inhibited PMN fungistatic activity against $\mathrm{Hc}$ yeasts (data not shown). In addition, when PMN and opsonized Hc yeasts were incubated for $24 \mathrm{~h}$ at $37^{\circ} \mathrm{C}$, no nitrite could be detected in the medium, even when $5 \mathrm{mM} \mathrm{L}$-arginine was added to the medium (data not shown). Likewise, when PMN and Hc yeasts were incubated for $24 \mathrm{~h}$ in the presence of the respiratory burst inhibitors SOD $(40 \mu \mathrm{g} / \mathrm{ml})$, catalase $(100 \mu \mathrm{g} / \mathrm{ml})$, or mannitol $(0.04 \mathrm{M})$, PMN fungistatic activity against $\mathrm{Hc}$ yeasts was not inhibited (data not shown).

Fungistatic activity of CGD PMN against Hc yeasts. Overall, these data suggested that PMN-mediated fungistasis was mediated by a nonoxidative mechanism(s). In neutrophils from CGD patients, the capacity to produce superoxide and related microbicidal oxygen metabolites is impaired by NADPH oxidase deficiency (30-32). Therefore, to explore this hypothesis, the fungistatic activity of PMN from three patients with CGD was compared with the fungistatic activity of three normal controls. At all ratios of PMN/yeast tested, the fungistatic activity of CGD PMN was equivalent to the fungistatic activity of the normal controls. Table II shows the data obtained using a PMN/yeast ratio of 10:1.

Inhibition of PMN fungistatic activity by ammonium chloride. PMN respiratory burst products did not appear to play a role in inhibiting the growth of Hc yeasts. Therefore, we sought to obtain preliminary evidence that lysosomal hydrolases or cationic peptides of the specific and azurophil granules might mediate fungistasis by PMN. The activity of these antimicrobial proteins can be inhibited by the lysosomotropic agent $\mathrm{NH}_{4} \mathrm{Cl}$, which inhibits phagosome acidification (33) and phagosome-lysosome fusion (34). Therefore, PMN were preincubated for $1 \mathrm{~h}$ at $37^{\circ} \mathrm{C}$ with varying concentrations of $\mathrm{NH}_{4} \mathrm{Cl}$. Yeasts were then added, and the mixture was incubated for 24 h at $37^{\circ} \mathrm{C}$. Fig. 4 shows that the presence of $\mathrm{NH}_{4} \mathrm{Cl}$ in the incubation medium inhibited PMN fungistatic activity against Hc yeasts in a concentration-dependent manner.

Ammonium chloride $(50 \mathrm{mM})$ alone did not effect the growth of yeasts in culture medium (data not shown). How-

Table II. PMN from CGD Patients Are Fungistatic against Hc Yeasts

\begin{tabular}{|c|c|c|}
\hline \multirow[b]{2}{*}{ Experiment } & \multicolumn{2}{|c|}{ Percent inhibition of growth } \\
\hline & Control & CGD \\
\hline 1 & $98.3 \pm 0.1^{*}$ & $99.4 \pm 0.2$ \\
\hline 2 & $72.4 \pm 2.1$ & $97.5 \pm 0.2$ \\
\hline 3 & $87.4 \pm 1.7$ & $95.8 \pm 0.3$ \\
\hline
\end{tabular}

Neutrophils from CGD patients or normal controls were incubated with $\mathrm{Hc}$ yeasts at a ratio of $10: 1$ for $24 \mathrm{~h}$ at $37^{\circ} \mathrm{C}$. ${ }^{*}$ Mean $\pm \mathrm{SD}$ of triplicate determinations. 


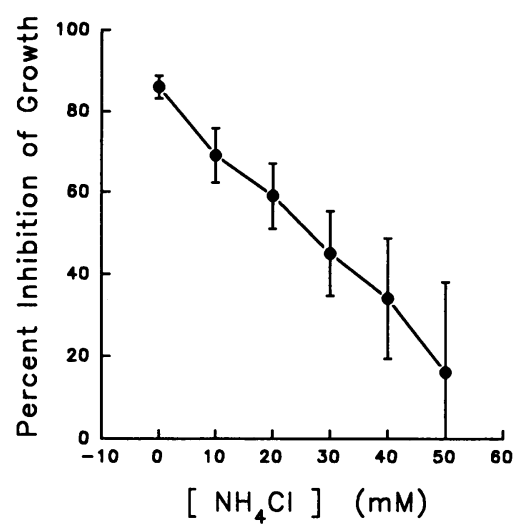

ever, with increasing concentrations of $\mathrm{NH}_{4} \mathrm{Cl}$, the percentage of viable PMN did decrease, but the total number of PMN/ well remained constant. At $50 \mathrm{mM} \mathrm{NH}_{4} \mathrm{Cl}, 50 \%$ of $\mathrm{PMN}$ were nonviable as determined by trypan blue dye exclusion (mean of two experiments). Since the ratio of PMN to yeasts in these experiments initially was $50: 1$, the remaining effective ratio of viable PMN to yeasts was 25:1. As maximum fungistasis was achieved at a PMN to yeast ratio of 10:1 (Fig. 1), the inhibition of PMN-mediated fungistasis by $\mathrm{NH}_{4} \mathrm{Cl}$ cannot be accounted for by its toxicity to PMN.

Fungistatic activity of subcellular fractions of PMN. We next sought to identify the specific subcellular fraction(s) of PMN that mediated fungistatic activity against $\mathrm{Hc}$ yeasts. Four fractions were obtained from lysed PMN for these studies: cytosol and freeze/thaw extracts of the plasma membrane, and of the specific and azurophil granules. In initial experiments, PMN fractions were incubated at $37^{\circ} \mathrm{C}$ for $24 \mathrm{~h}$ with $\mathrm{Hc}$ yeasts at a ratio of 100 cell equivalents per yeast. As shown in Table III, incubation of yeasts with the azurophil granule fraction resulted in $95 \%$ inhibition of growth. In contrast, incubation of Hc yeasts with cytosol, plasma membrane, or the specific granule fractions actually increased the growth of yeasts compared with their growth in medium alone. In addition, intact azurophil granules did not exhibit fungistatic activity against $\mathrm{Hc}$ yeasts (data not shown).

Extracts of azurophil granules mediated fungistatic activity against Hc yeasts in a concentration-dependent manner (Fig. 5 ) and over a pH range of 4 to 8 (Table IV). In contrast, incubation of Hc yeasts with neutrophil cytosol, plasma membrane, or specific granule fractions under a wide variety of conditions always increased the growth of yeasts compared with growth in the medium control (data not shown).

Table III. Fungistatic Activity of Subcellular Fractions of PMN against Hc Yeasts

\begin{tabular}{lc}
\hline Subcellular fraction & Percent inhibition of growth \\
\hline Azurophil granules & $95 \pm 1.5^{*}$ \\
Specific granules & $1.6 \times$ increase $^{*}$ \\
Plasma membrane & $2.8 \times$ increase $^{\dagger}$ \\
Cytosol & $50 \times$ increase $^{\dagger}$
\end{tabular}

${ }^{*} \operatorname{Mean} \pm \operatorname{SEM}(n=9) .{ }^{\dagger} \operatorname{Mean} \pm \operatorname{SEM}(n=4)$.

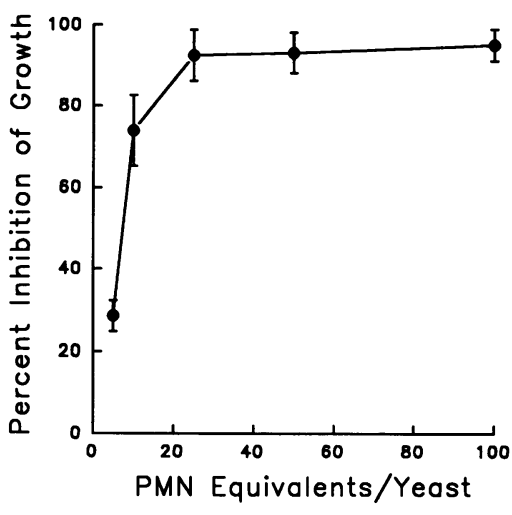

Figure 5. The azurophil granule fraction of PMN mediates fungistasis against $\mathrm{Hc}$ yeasts in a concentration-dependent manner. 5 $\times 10^{3}$ yeasts were incubated with varying cell equivalents of the azurophil granule fraction for $24 \mathrm{~h}$ at $37^{\circ} \mathrm{C}$, and fungistasis quantified as described in Methods. The data are the mean \pm SEM of three experiments.

In earlier experiments, Hc yeasts overcame PMN-mediated fungistasis only after $5 \mathrm{~d}$ in culture. Therefore, we sought to determine the length of time required for $\mathrm{Hc}$ yeasts to overcome the fungistatic activity of the isolated azurophil granule fraction. The azurophil granule fraction and yeasts at a ratio of 50 cell equivalents per yeast were incubated at $37^{\circ} \mathrm{C}$ for $1-7 \mathrm{~d}$, and the growth of yeasts quantified as described in Methods. The data in Fig. $6 \mathrm{~A}$ demonstrate that under the culture conditions of the assay, yeasts grew continuously over the 7-d incubation period. In contrast, the growth of yeasts incubated in the presence of the azurophil granule fraction was inhibited by $>90 \%$ at all time points tested (Fig. $6 \mathrm{~B}$ ).

\section{Discussion}

The role of neutrophils in host defense against $H$. capsulatum remains obscure. Clearly, PMN are part of the inflammatory response to $\mathrm{Hc}$ in animal models of histoplasmosis $(2,3)$. However, because most individuals possess cell-mediated immunity to the fungus in areas where $\mathrm{Hc}$ is endemic, the specific role of $\mathrm{PMN}$ in the immune response to $\mathrm{Hc}$ is unclear. Despite the fact the initial infection with Hc may cause only mild symptoms, most individuals develop cell-mediated immunity. There are, however, many individuals living in areas where Hc is endemic who are skin test negative when tested with histoplasmin, but who presumably have been exposed to $\mathrm{Hc}$ at some point during their lifetimes. Thus, it is reasonable to postulate that in some cases the initial inflammatory response, of which PMN are a major part, may be sufficient to clear the organism from the host, or that the initial inoculum was too small to induce longlasting immunity.

Table IV. Effect of pH on the Fungistatic Activity of the PMN Azurophil Granule Fraction

\begin{tabular}{cc}
\hline pH & Percent inhibition of growth \\
\hline 4 & $92 \pm 3.2^{*}$ \\
5 & $94 \pm 1.8$ \\
6 & $96 \pm 1.6$ \\
7 & $95 \pm 1.7$ \\
8 & $88 \pm 4.9$
\end{tabular}

* Mean \pm SEM $(n=5)$. 

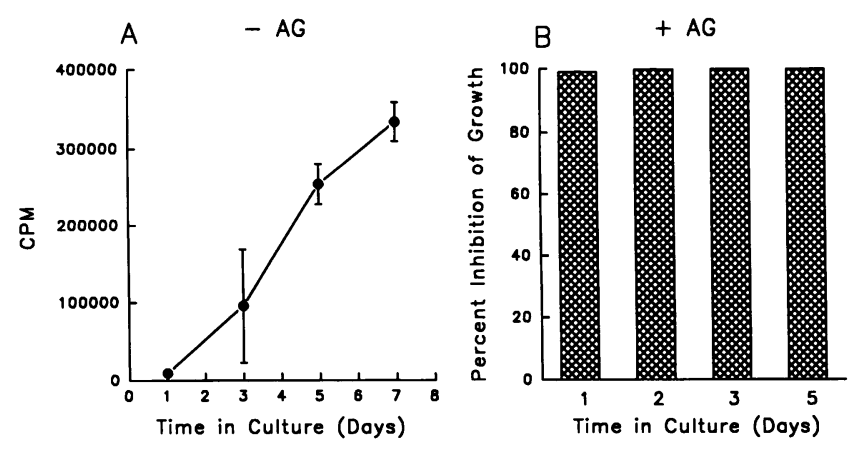

Figure 6. Azurophil granule-mediated fungistasis against Hc yeasts persists for up to $7 \mathrm{~d}$. The azurophil granule fraction and $\mathrm{Hc}$ yeasts at a ratio of 50:1 (cell equivalents per yeast) were incubated at $37^{\circ} \mathrm{C}$ for 1-7 d. $A$ shows the growth of yeasts incubated in medium alone. $B$ shows the inhibition of growth mediated by the azurophil granule fraction. The data are the mean \pm SEM of three experiments.

The data presented here demonstrate that, in vitro, human neutrophils possess potent fungistatic activity against Hc yeasts. Neutrophil-mediated fungistasis was evident as early as $2 \mathrm{~h}$ and was detectable at PMN:yeast ratios as low as 1:2. Maximum PMN-mediated fungistasis was achieved at PMN:yeast ratios of 10:1 to 50:1 and after $24 \mathrm{~h}$ of incubation. Remarkably, neutrophils were able to sequester yeasts intracellularly for as long as $5 \mathrm{~d}$. Only on the sixth day of culture were yeasts observed extracellularly. In contrast to PMN, Hc yeasts grew better within freshly isolated monocytes than in tissue culture medium. Furthermore, when human monocyte-derived $\mathbf{M} \phi$ are incubated with $\mathrm{Hc}$ yeasts at a low multiplicity of infection such that $20-25 \%$ of the $\mathbf{M} \phi$ are infected, the monolayers are destroyed in 3-4 d (17).

PMN-mediated fungistasis required the presence of either fresh or heat-inactivated human serum. This data correlates with our previous experiments (9), which demonstrated that although unopsonized Hc yeasts bound to PMN CD18 receptors, opsonization of yeasts with fresh serum or heat-inactivated serum was required for phagocytosis.

Despite the serum requirement for PMN to inhibit the growth of yeasts, ingestion of the yeasts per se was not required. Thus, PMN-mediated fungistasis was equivalent in the presence or absence of $\mathrm{CD}$, an actin microfilament inhibitor that prevents phagocytosis (35-37). Clearly, however, the yeasts bound to neutrophils, and binding was sufficient to induce signal transduction and PMN-mediated fungistasis.

Attachment of serum opsonized Hc yeasts to neutrophils was mediated predominantly via $\mathrm{CR}_{1}$ and $\mathrm{CR}_{3}$ (CD11b). Thus, preincubation of adherent PMN with antibodies to $C_{1}$ and $\mathrm{CR}_{3}$ inhibited yeast binding by $33 \%$ and $34 \%$, respectively. The inhibition mediated by a mixture of anti-CR $\mathrm{CR}_{1}$ and anti$\mathrm{CR}_{3}$ was additive and inhibited the attachment of yeasts to PMN by $63 \%$.

Heat-inactivated serum promoted PMN-mediated fungistasis almost as well as fresh complement preserved serum. Thus, engagement of the neutrophil FcR alone is sufficient to stimulate PMN fungistatic activity against Hc yeasts. When yeasts were opsonized in fresh serum, a mAb to FcRIII inhibited yeast binding by $22 \%$, and a combination of antibodies to $\mathrm{CR}_{1}, \mathrm{CR}_{3}$, and FcRIII inhibited the attachment of yeasts to
PMN by $76 \%$. Thus, the FcR also participates in PMN-mediated fungistasis when the yeasts are opsonized in fresh serum.

The role of other membrane receptors in PMN-mediated fungistasis is less clear. Unopsonized yeasts are recognized by all three neutrophil CD18 receptors (9), and antibodies to CD1 la (LFA-1) and CD11c (p150,95) inhibited yeast binding to $\mathrm{PMN}$ by $16 \%$ and $11 \%$, respectively. Thus, these receptors also may play a small role in the attachment of opsonized yeasts to neutrophils.

Although freshly isolated and unactivated neutrophils inhibited the growth of Hc yeasts by $85 \%$ to $95 \%$, we sought to induce PMN-mediated fungicidal activity against Hc yeasts with various cytokines. Cytokines were chosen that are known to augment the respiratory burst or cytotoxic activities of neutrophils (38-43). However, coculture of PMN and Hc yeasts with IFN $\gamma$, IL-8, IL-3, GM-CSF, G-CSF, or PMA failed to induce PMN fungicidal activity or enhance PMN-mediated fungistasis. Furthermore, endogenous PMN fungistatic activity was not blocked by agents known to inhibit the respiratory burst or by inhibitors of NO synthetase.

Thus, despite the fact that opsonized Hc yeasts stimulate the neutrophil respiratory burst $(6,9)$, and although $\mathrm{Hc}$ yeasts are killed in vitro by a combination of $\mathrm{H}_{2} \mathrm{O}_{2}, \mathrm{Fe}^{2+}$, and iodide (6), or $\mathrm{H}_{2} \mathrm{O}_{2}$, horseradish peroxidase, and iodide $(4,7, \mathrm{~S}$. L. Newman and L. Gootee, unpublished observations), these data suggested that PMN fungistatic activity against Hc yeasts is mediated by a nonoxidative mechanism(s). This idea was strongly supported by the fact that the fungistatic activity of PMN from three CGD patients was equivalent to that mediated by three normal controls. In addition, preincubation of PMN with the lysosomotropic agent ammonium chloride inhibited PMN-mediated fungistasis in a concentration-dependent manner.

The major components of the neutrophil that mediate nonoxidative antimicrobial activity are the lysosomal hydrolases and cationic peptides that reside in the specific and azurophil granules (44-46). Studies of these and other subcellular fractions of PMN demonstrated that the principal component of the fungistatic activity of human neutrophils resides in the azurophil granules. Azurophil granule-mediated fungistasis was concentration-dependent, persisted for up to $7 \mathrm{~d}$, and occurred over a wide $\mathrm{pH}$ range.

The fact that Hc yeasts readily multiply within human monocytes and macrophages (17) indicates that neutrophil azurophil granules must contain some enzymes or cationic peptides not found in these phagocytes. Likely candidates are the cationic peptides known as "defensins" $(45,46)$. Although defensins have been found in macrophages from other mammalian species, human macrophages do not contain these antimicrobial agents $(45,46)$. Other potential candidates contained in the azurophil granules include azurocidin (47), bactericidal permeability-increasing protein (48), and cathepsin $G$ (49). One or a combination of these neutrophil antibiotic proteins may be responsible for the potent antifungal activity of human PMN. Current efforts are directed toward identifying the specific enzymes or cationic peptides of azurophil granules that mediate fungistasis against $\mathrm{Hc}$ yeasts.

The potent fungistatic activity against $\mathrm{Hc}$ yeasts exhibited by human neutrophils in vitro suggests that PMN may play an important role in host defense against $\mathrm{Hc}$ in vivo. Certainly the data indicate that neutrophils may be capable of slowing the 
course of the infection, and under certain circumstances they may prevent dissemination of the yeasts from the lung. It is also possible that neutrophils may damage the yeasts in such a manner as to render them vulnerable to inflammatory macrophages. Thus, inflammatory macrophages may phagocytose yeast-containing neutrophils (50), and subsequently kill the partially damaged yeasts. Either or both of these postulated mechanisms of defense involving neutrophils during the early phase of the inflammatory response to $\mathrm{Hc}$ may explain, at least in part, the fact that a substantial percentage of pulmonary infections by this organism are subclinical and self-limiting.

\section{Acknowledgments}

The authors wish to thank Drs. R. Gruppo, R. Harris, and R. Broughton for making their patients available for study, and Dr. Ward Bullock for critical review of the manuscript.

This work was supported by NIH Grants AI-28392 and AI-23807, and a grant from the Western-Southern Foundation.

This manuscript is dedicated to the memory of Robert Schnur, my friend and colleague, who initiated this intriguing line of investigation.

\section{References}

I. Deepe, G. S., Jr., and W. E. Bullock. 1992. Histoplasmosis: a granulomatous inflammatory response. In Inflammation: Basic Principles and Clinical Correlates. J. I. Gallin, I. M. Goldstein, and R. Snyderman, editors. Raven Press, New York. 943-958.

2. Procknow, J. J., M. I. Page, and C. G. Loosli. 1960. Early pathogenesis of experimental histoplasmosis. Arch. Pathol. 69:413-426.

3. Baughman, R. P., C. K. Kim, A. Vinegar, D. E. Hendricks, D. J. Schmidt, and W. E. Bullock. 1986. The pathogenesis of experimental pulmonary histoplasmosis. Correlative studies of histopathology, bronchoalveolar lavage, and respiratory function. Am. Rev. Respir. Dis. 134:771-776.

4. Howard, D. H. 1973. Fate of Histoplasma capsulatum in guinea pig polymorphonuclear leukocytes. Infect. Immun. 8:412-419.

5. Kwon-Chung, K. J., R. P. Tewari, and W. K. Tom. 1982. Determination of viability of Histoplasma capsulatum yeast cells: comparison between dye exclusion and colony count methods. J. Med. Vet. Mycol. 25:107-114.

6. Schaffner, A., C. E. Davis, T. Schaffner, M. Markert, H. Douglas, and A. I. Braude. 1986. In vitro susceptibility of fungi to killing by neutrophil granulocytes discriminates between primary pathogenicity and opportunism. J. Clin. Invest. 78:511-524.

7. Brummer, E., N. Kurita, S. Yoshida, K. Nishimura, and M. Miyaji. 1991. Fungistatic activity of human neutrophils against Histoplasma capsulatum: correlation with phagocytosis. J. Infect. Dis. 164:158-162.

8. Kurita, N., E. Brummer, S. Yoshida, K. Nishimura, and M. Miyaji. 1991. Antifungal activity of murine polymorphonuclear neutrophils against Histo plasma capsulatum. J. Med. Vet. Mycol. 29:133-143.

9. Schnur, R. A., and S. L. Newman. 1990. The respiratory burst response to Histoplasma capsulatum by human neutrophils. Evidence for intracellular trapping of superoxide anion. J. Immunol. 144:4765-4772.

10. Todd, R. F. 1986. Monoclonal antibodies that identify Mol and LFA-1, two human leukocyte membrane glycoproteins: a review. In Leukocyte Typing II. Volume 3. E. L. Rheinerz, B. F. Haynes, L. M. Nadler, and I. D. Bernstein editors. Springer-Verlag, Inc., New York, New York. 95-108.

11. Wright, S. D., P. E. Rao, W. C. Van Voorhis, L. S. Craigmyle, K. Iida, M. A. Talle, E. F. Westberg, G. Goldstein, and S. C. Silverstein. 1983. Identification of the $\mathrm{C} 3$ bi receptor of human monocytes and macrophages by using monoclonal antibodies. Proc. Natl. Acad. Sci. USA. 80:5699-5703.

12. Fleit, H. B., S. D. Wright, and J. C. Unkeless. 1982. Human neutrophil Fc-receptor distribution and structure. Proc. Natl. Acad. Sci. USA. 79:32753279.

13. Eddy, A., S. L. Newman, F. Cosio, T. LeBien, and A. Michael. 1984. The distribution of the CR3 receptor on human cells and tissue as revealed by a monoclonal antibody. Clin. Immunol. Immunopathol. 31:371-389.

14. Lanier, L. L., M. A. Arnaout, R. Schwarting, N. L. Warner, and G. D. Ross. 1985. p1 50,95, third member of the LFA-1 /CR3 polypeptide family identified by anti-LeuM5 monoclonal antibody. Eur. J. Immunol. 15:713-718.

15. Dobson, N. J., J. D. Lambris, and G. D. Ross. 1981. Characteristics of isolated erythrocyte complement receptor type $1\left(\mathrm{CR}_{1}, \mathrm{C} 4 \mathrm{~b}-\mathrm{C} 3 \mathrm{~b}\right.$ receptor $)$ and $\mathrm{CR}_{1}$-specific antibodies. J. Immunol. 126:693-698.

16. Worsham, P., and W. E. Goldman. 1988. Quantitative plating of Histoplasma capsulatum without addition of conditioned medium or siderophores. $J$ Med. Vet. Mycol. 26:137-143.

17. Newman, S. L., L. Gootee, C. Bucher, and W. E. Bullock. 1991. Inhibition of intracellular growth of Histoplasma capsulatum yeasts cells by cytokine-activated human monocytes and macrophages. Infect. Immun. 59:737-741.

18. Newman, S. L., C. Bucher, J. Rhodes, and W. E. Bullock. 1990. Phagocytosis of Histoplasma capsulatum yeasts and microconidia by human cultured macrophages and alveolar macrophages. Cellular cytoskeleton requirement for attachment and ingestion. J. Clin. Invest. 85:223-230.

19. Gabay, J. E., J. M. Heiple, Z. A. Cohn, and C. F. Nathan. 1986. Subcellular location and properties of bactericidal factors from human neutrophils. $J$. Exp. Med. 164:1407-1421.

20. Newman, S. L., and L. Gootee. 1992. Colony-stimulating factors activate human macrophages to inhibit intracellular growth of Histoplasma capsulatum yeasts. Infect. Immun. 60:4593-4597.

21. Wright, S. D., S. M. Levin, M. T. C. Jong, Z. Chad, and L. G. Kabbash. 1989. $\mathrm{CR}_{3}$ (CD1 lb/CD18) expresses one binding site for Arg-Gly-Asp-containing peptides and a second site for bacterial lipopolysaccharide. J. Exp. Med. 169:175-183.

22. Salvemini, D., G. De Nucci, R. J. Gryglewski, and J. R. Vane. 1989. Human neutrophils and mononuclear cells inhibit platelet aggregation by releasing a nitric oxide-like factor. Proc. Natl. Acad. Sci. USA. 86:6328-6332.

23. Schmidt, H. H. H. W., R. Seifert, and E. Bohme. 1989. Formation and release of nitric oxide from human neutrophils and HL-60 cells induced by a chemotactic peptide, platelet activating factor and leukotriene $\mathrm{B}_{4}$. FEBS (Fed. Eur. Biochem. Soc.) Lett. 244:357-360.

24. Wright, C. D., A. Mulsch, R. Busse, and H. Osswald. 1989. Generation of nitric oxide by human neutrophils. Biochem. Biophys. Res. Commun. 160:813819.

25. Nathan, C. F., and J. B. Hibbs, Jr. 1991. Role of nitric oxide synthesis in macrophage antimicrobial activity. Curr. Opin. Immunol. 3:65-70.

26. Green, S. J., S. Mellouk, S. L. Hoffman, M. S. Meltzer, and C. A. Nacy. 1990. Cellular mechanisms of nonspecific immunity to intracellular infection: cytokine-induced synthesis of toxic nitrogen oxides from L-arginine by macrophages and hepatocytes. Immunol. Lett. 25:15-20.

27. Palmer, R. M. J., D. D. Rees, D. S. Ashton, and S. Moncada. 1988. L-arginine is the physiological precursor for the formation of nitric oxide in endothelium-dependent relaxation. Biochem. Biophys. Res. Commun. 153: 1251-1256.

28. Olken, N. M., K. M. Rusche, M. K. Richards, and M. A. Marletta. 1991. Inactivation of macrophage nitric oxide synthetase activity by $\mathrm{N}^{\mathrm{G}}$-methyl-arginine. Biochem. Biophys. Res. Commun. 177:828-833.

29. Stuehr, D. J., O. A. Fasehun, N. S. Kwon, S. S. Gross, J. A. Gonzalez, R Levi, and C. F. Nathan. 1991. Inhibition of macrophage and endothelial cell nitric oxide synthetase by diphenyleneiodonium and its analogues. FASEB (Fed. Am. Soc. Exp. Biol.) J. 5:98-103.

30. Baehner, R. L., and D. G. Nathan. 1967. Leukocyte oxidase: defective activity in chronic granulomatous disease. Science (Wash. D.C.). 155:835-837.

31. Curnutte, J. T., D. M. Whitten, and B. M. Babior. 1974. Defective superoxide production by granulocytes from patients with chronic granulomatous disease. N. Engl. J. Med. 290:593-597.

32. Curnutte, J. T., R. S. Kipnes, and B. M. Babior. 1975. Defect in pyridine nucleotide-dependent superoxide production by a particulate fraction from the granulocytes of patients with chronic granulomatous disease. $N$. Engl. J. Med. 293:628-632.

33. Ohkuma, S., and B. Poole. 1978. Fluorescence probe measurement of the lysosomal $\mathrm{pH}$ in living cells and the perturbation of $\mathrm{pH}$ by various agents. Proc. Natl. Acad. Sci. USA. 75:3327-3331.

34. Gordon, A. H., P. D'Arcy Hart, and M. R. Young. 1980. Ammonia inhibits phagosome-lysosome fusion in macrophages. Nature (Lond.). 286:7980.

35. Puszkin, E., S. Puszkin, L. W. Lo, and S. W. Tannenbaum. 1973. Binding of cytochalasin D to platelet and muscle myosin. J. Biol. Chem. 248:7754-7761.

36. Malawista, S. E., J. B. L. Gee, and K. G. Bensch. 1971. Cytochalasin B reversibly inhibits phagocytosis: functional, metabolic, and ultrastructural effects in human blood leukocytes and rabbit alveolar macrophages. Yale J. Biol. Med. 44:286-300.

37. Newman, S. L., L. K. Mikus, and M. A. Tucci. 1991. Differential requirements for cellular cytoskeleton in human macrophage complement receptor-and Fc receptor-mediated phagocytosis. J. Immunol. 146:967-974.

38. Weisbart, R. H., D. W. Golde, S. C. Clark, G. G. Wong, and J. C. Gasson 1985. Human granulocyte-macrophage colony-stimulating factor is a neutrophil activator. Nature (Lond.). 314:361-363.

39. Nathan, C. F. 1989. Respiratory burst in adherent human neutrophils: Triggered by colony-stimulating factors CSF-GM and CSF-G. Blood. 73:301306. 
40. Balazovich, K. J., H. I. Almeida, and L. A. Boxer. 1991. Recombinant human G-CSF and GM-CSF prime human neutrophils for superoxide production through different signal transduction mechanisms. J. Lab. Clin. Med. 118:576-584.

41. Baggiolini, M., A. Walz, and S. L. Kunkel. 1989. Neutrophil-activating peptide-1/interleukin 8, a novel cytokine that activates neutrophils. J. Clin. Invest. $84: 1045-1049$.

42. Shalaby, M. R., B. G. Aggarwal, E. Rinderknecht, L. P. Svedersky, B. S. Finkle, and M. A. Palladino, Jr. 1985. Activation of human polymorphonuclear functions by interferon- $\gamma$ and tumor necrosis factors. J. Immunol. 135:20692073.

43. Steinbeck, M. J., and J. A. Roth. 1989. Neutrophil activation by recombinant cytokines. Rev. Infect. Dis. 11:549-568.

44. Henson, P. M., J. E. Henson, C. Fittschen, G. Kimani, D. L. Bratton, and D. W. Riches. 1988. Phagocytic cells: degranulation and secretion. In Inflammation: Basic Principles and Clinical Correlates. J. I. Gallin, I. M. Goldstein, and R. Snyderman, editors. Raven Press, New York. 363-390.
45. Spitznagel, J. K. 1990. Antibiotic proteins of human neutrophils. J. Clin Invest. 86:1381-1386.

46. Ganz, T., M. E. Selsted, and R. I. Lehrer. 1990. Defensins. Eur. J. Haema tol. $44: 1-8$.

47. Campanelli, D., P. A. Detmers, C. F. Nathan, and J. E. Gabay. 1990 Azurocidin and a homologous serine protease from neutrophils. Differential antimicrobial and proteolytic properties. J. Clin. Invest. 85:904-915.

48. Weiss, J., P. Elsbach, I. Olsson, and H. Odeberg. 1978. Purification and characterization of a potent bactericidal and membrane active protein from the granules of human polymorphonuclear leukocytes. J. Biol. Chem. 253:26442672.

49. Odeberg, H., and I. Olsson. 1975. Antibacterial activity of cationic proteins from human granulocytes. J. Clin. Invest. 56:1118-1124.

50. Newman, S. L., J. E. Henson, and P. M. Henson. 1982. Phagocytosis of senescent neutrophils by human monocyte-derived macrophages and rabbit inflammatory macrophages. J. Exp. Med. 156:430-442. 